\title{
Educational Enquiry Desk
}

\author{
Nikhil Jadhav $^{1}$, Pravin Jadhav ${ }^{2}$, Ashish Jagtap ${ }^{3}$, K.K. Tripathi ${ }^{4}$ \\ Student, Department of Computer Engg, Shivajirao S. Jondhale College of Engg, Dombivli(E), India ${ }^{1,2,3}$ \\ Assistance Professor, Department of Computer Engg, Shivajirao S. Jondhale College of Engg, Dombivli(E), India ${ }^{4}$
}

\begin{abstract}
Changes in Information Technology (IT) allows schools to utilize database and application such as student information system (SIS) thus, making the accessing of records. One of the changes that came about is this system is a web application which provides answer to the query of student. Students just have to query through the bot which used for chatting. The proposed system is a web application to manage student's details and keeping them updated about latest events in college. The application will be used by teachers, students and parents. The utilities provided by the applications are- the user can query any college related activities through the system. The user does not have to personally go to the college for enquiry. The system analyzes the question and then answers to user. The user just has to register himself to the system and has to login to the system . After login user can access to the various helping pages. This system helps the student to be updated about the college activities.
\end{abstract}

Keywords: utilize databases, chat bot, analyzes the question, login the system.

\section{INTRODUCTION}

User interfaces for software applications can come in a variety of formats, ranging from command-line, graphical, web application, and even voice. While the most popular user interfaces include graphical and web-based applications, occasionally the need arises for an alternative interface. Whether due to multi-threaded complexity, concurrent connectivity, or details surrounding execution of the service, a chat bot based interface may suit the need. Chat bots typically provide a text-based user interface, allowing the user to type commands and receive text responses. Chat bots are usually state full services, remembering previous commands (and perhaps even conversation) in order to provide functionality.

A popular example from recent Internet history is the usage of IRC chat bots, often used for monitoring chat rooms, playing games, and providing help. The same technology can be used today, but to provide even more powerful functionality, such as serving business processing requests, multi-threaded processing, or any multi-threaded task that may not be ideal within a web application. When chat bot technology is integrated with popular web services it can be utilized securely by an even larger audience.

\section{PROBLEM WITH CURRENT SCENARIO}

Traditionally, the chat bot system is not known to people who are not more into the technology. Even if there exist a chat bot system, it is not much accurate in proving the answer or solutions. Students need to manually visit to the college to get their queries answered by the college help desk. This process consumes lot of time as well as money as the customer needed to visit college if its miles away from home. Also, this process may lead to communication gap between student and college.

\section{DRAWBACKS OF EXISTING SYSTEM}

- Lack of accuracy and error prone.

- Overall efficiency is less.

- Non-secure.

- No perfect maintenance of records.

- No method to trace details.

- Human errors.

- The manual system is too slow.

- Searching is more time consuming.

\section{PROPOSED SYSTEM}

- A Student bot project is built using artificial algorithms that analyzes user's queries and understand user's message.

- This system is a web application which provides answer to the query of the student.

- Students just have to query through the bot which is used for chatting.

- Students can chat using any format there is no specific format the user has to follow.

- The System uses built in artificial intelligence to answer the query.

- The answers are appropriate what the user queries.

- If the answer found to invalid, user just need to select the invalid answer button which will notify the admin about the incorrect answer.

- All the registered students view time-table, syllabus, general notice, exam time-table and exam notice.

- Admin can view invalid answer through portal via login

- System allows admin to delete the invalid answer or to add a specific answer of that equivalent question.

- Chat bot will have 5 section for keyword.Admin needs to fill at least 2 keywords with its answer. 
E.g.:

Q) What will be date for Coms SEM 3 Exam

(Keywords: Date, Coms, Sem3, Exam)

Ans) 2016/11/08. (Assumed this date is entered by admin)

- Admin can add students, add/manage course details, Upload Time-Table image, Upload Syllabus image, 2. Upload General Notice in form of image/pdf, Upload 0 Exam Time-Table and Uploads Exam Notice.

- The student can query any college related activities through the system using forum.

- The student does not have to personally go to the college for enquiry.

- The System analyzes the question and then answers to the student.

- The system answers to the query as if it is answered by the person.

- With the help of artificial intelligence, the system answers the query asked by the students.

- The system replies using an effective Graphical user interface which implies that as if a real person is talking to the student.

- The student can query about the college related activities through online with the help of this web application.

- This system helps the student to be updated about the college activities.

\section{V.SYSTEM MODULES}

The system comprises of 2 major modules with their submodules as follows:

1. Admin: Admin has to login to the system to access various pages given below.

- Add Student: the system.

Can add new student with personal details into

- Add / Manage Course:

- $\quad$ Can add a new course details or can manage the pre-added course.

- Upload Time-Table Image:

- $\quad$ Can upload an image of the time-table of various standards/Classes.

○ Upload Syllabus Image:

academics

Can upload image of syllabus for various

- Upload General Notice: of image/pdf

Here, admin can upload a general notice in form

- Upload Exam Time Table Image:

Can upload image of exam time-table of every

class.

- Upload Exam Notice Image:

- $\quad$ Can upload an image file of Exam Notice.

- Manage Chat Bot:

- $\quad$ System allows admin to view and edit chat bot.

Forum: $\begin{array}{ll}\text { - } & \text { Admin can chat with students using forum. } \\ - & \text { View Invalid Answer: } \\ \text { - } & \text { Can view all the invalid answers marked by the }\end{array}$ users.

Student:

Chat Bot + Forum:

User can chat with the bot it implies as if enquiring to the college person about college related activities.

- User has full authority to mark the answer as invalid if the answer doesn't match the question.

This will notify the admin which will be analyzed and then corrected.

- $\quad$ Using forum, user can ask question to the admin regarding the college activities or any other.

- View Time- Table:

- $\quad$ All the registered user can view the uploaded image of time-table by admin.

View Syllabus:

Users can view the syllabus of their academics in the form of image.

- View General Notice:

- $\quad$ Can view the notice or can download the pdf file.

- View Exam Time Table:

by the admin

Can view the exam time-table which is uploaded

- Exam Notice:

Can view exam notice which is uploaded by the admin.

\section{SYSTEM ARCHITECTURE}

This deals with the system block diagram of the Educational Enquiry Desk.

System architecture is a conceptual model that defines the structure, behavior, and more views of system. Figure1.shows that, a formal description and representation of a system, organized in a way that supports reasoning about the structure and behaviors of the system.

A system architecture can comprise system components that will work together to implement overall system.

\section{RESULTS}

This implementation is done on the server is done using .Net and visual studio, while the implementation of web application is using .Net.

In the module shown in figure 2 which helps to solve maximum queries related to organization, with a simple input output format

Using student login screen shown in figure. 3 The student can $\log$ in and ask any kind of information that is required.kindly provide a proper login id. 


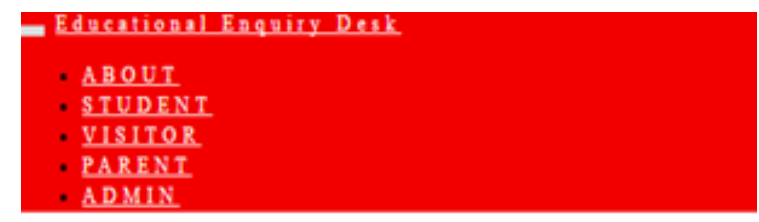

\section{Educational Enquiry Desk Happy to help!!}

Figure. 2 Home page

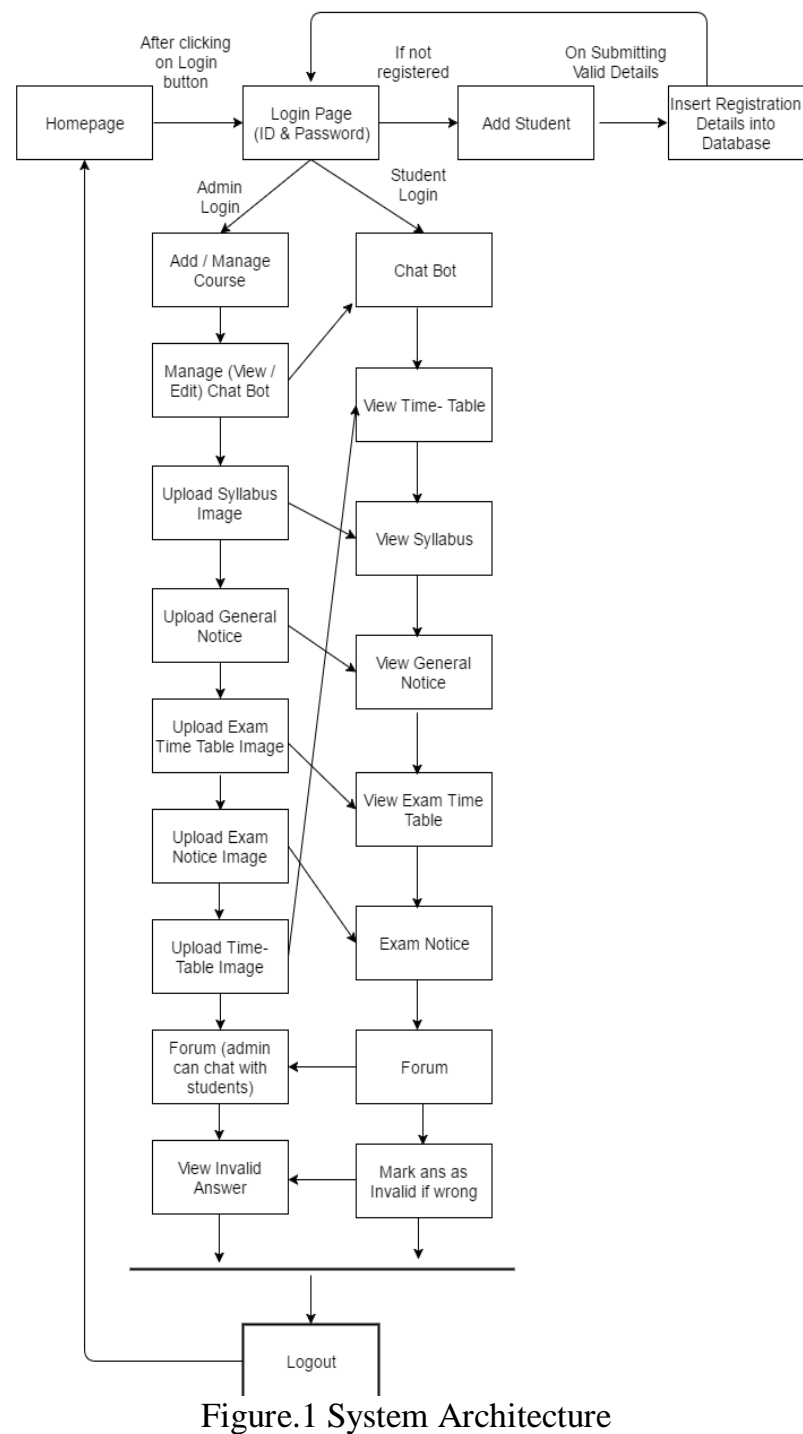

About Student

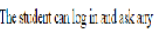

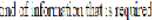

Kidy provide a goces logri it.

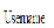

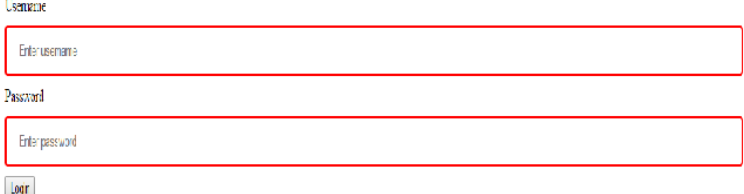

Figure. 3 Student Login

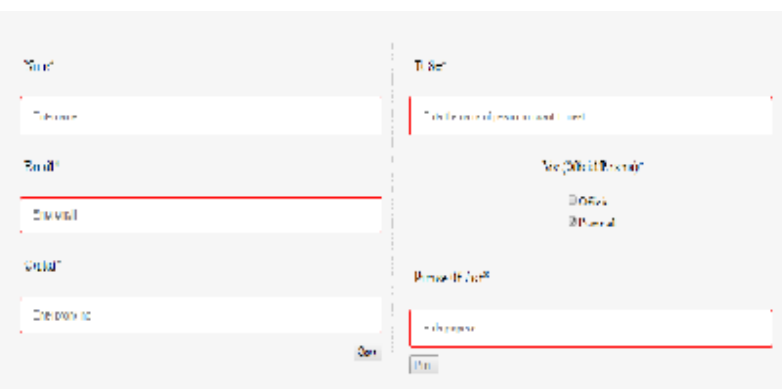

Figure 4. Visitors Page

Figure 4 shows visitors login page. Here visitor can login to the system, Information related to the visitor is stored here. Purpose of visit is also need to be mentioned. Figure 3 also provides the two options for visitors personal and official.

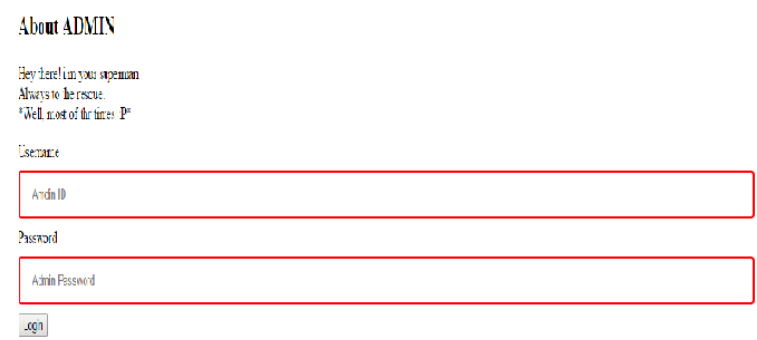

Figure 5. Admin Login

In the module shown in figure $5 \mathrm{Admin}$ has to login to the system to access various pages.
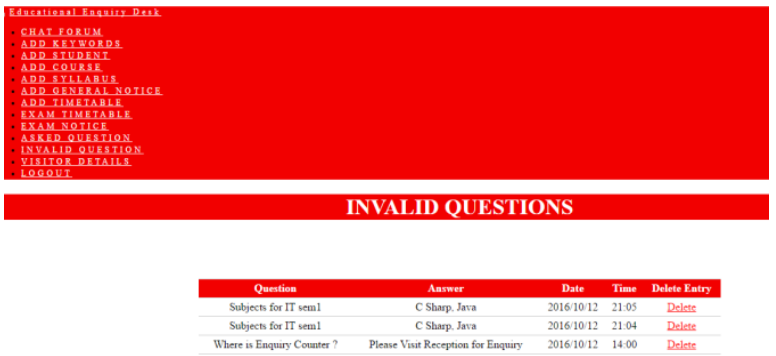

Figure 6 Admin Module

Figure 6 shows the Admin Module. In this module Admin can add students, manage course, Upload timetable, syllabus, Mange Chat Bot Etc.

Figure7 shows the Student Module. In this module Chat Bot is provided for student, student can view time table, view syllabus, view general notice, view exam time table.

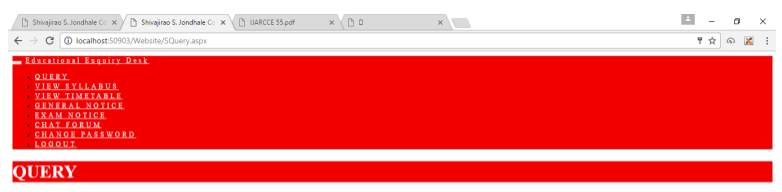

Namastey! How may we help you?

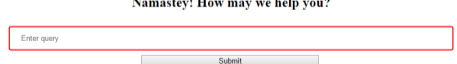

Figure 7 Student Module 


\section{TCHNOLOGIES USED}

1. Microsoft .net framework

The .NET Framework is a new computing platform that simplifies application development in the highly distributed environment of the Internet. The .NET Framework is designed to fulfill the following objectives:

- To provide a consistent object-oriented programming environment whether object code is stored and executed locally, executed locally but Internetdistributed, or executed remotely.

- To provide a code-execution environment that minimizes software deployment and versioning conflicts.

- To provide a code-execution environment that guarantees safe execution of code, including code created by an unknown or semi-trusted third party.

- To provide a code-execution environment that eliminates the performance problems of scripted or interpreted environments.

- To make the developer experience consistent across widely varying types of applications, such as Windows-based applications and Web-based applications.

2. Mysql (sql server)

Microsoft SQL Server is a Structured Query Language (SQL) based, client/server relational database. Each of these terms describes a fundamental part of the architecture of SQL Server.

\section{CONCLUSION}

The main objectives of the project were to develop an algorithm that will be used to identify answers related to user submitted questions. To develop a database were all the related data will be stored and to develop a web interface. The web interface developed had two parts, one for simple users and one for the administrator.

The following objectives were subsequently met. A background research took place, which included an overview of the conversation procedure and any relevant chat bots available. A database was developed, which stores information about questions, answers, keywords, $\operatorname{logs}$ and feedback messages. A usable system was designed, developed and deployed to the web server on two occasions. An evaluation took place from data collected by potential students of the University. Also after received feedback from the first deployment, extra requirements were introduced and implemented.

\section{REFERENCES}

[1] S.R. Bharamagoudar, Geeta R.B. and S.G Totad,- Web Based Student Information Management System, Andhra Pradesh, vol. 2, June 2013

[2] IEEE - Android Based Smart Learning and Attendance Management System, June 2015, 4655
[3] http://students.iitk.ac.in/eclub/assets/documentations/summer12/cha t-bot.pdf

[4] Vishal Bhalla, Tapodhan Singla, AnkitGahlot and Vijay Gupta, "Bluetooth Based Attendence Management System", International Journal of Innovations in Engineering and Technology (IJIET) Vol.3 Issue 1 October 2013, ISSN:2319-1058.

[5] Saurabh Walia and Satinderjit kaur Gill, -A Framework for Web Based Student Record Management System using PHP, Himachal Pradesh, vol. 3, August 2014. 